\title{
Design And Implementation of Group Tourist Monitoring Application With Realtime Database Firebase
}

\author{
I K G Sudiartha ${ }^{1}$, I N E Indrayana ${ }^{2}$, I W Suasnawa ${ }^{3}$, P I Ciptayani ${ }^{4}$ \\ Electrical Engineering Department \\ Politeknik Negeri Bali \\ Bali, Indonesia \\ 1eitutde@pnb.ac.id
}

\begin{abstract}
The purpose of this study was to determine the stages of creating a group tourist monitoring application using Firebase Realtime Database. Foreign tourists tend to visit Bali in groups and choose tour packages offered by the travel. During a tour at a tourist site, tourists are often too far away from the group and are confused to go back to search for a group or tour leader. One way to overcome this problem is to utilize information technology by building a mobile-based application This application is intended for tourists who visit the place of tour in groups (group tour). Before starting the tour, every tourist will be lent a smart phone. In the smart phone there are android-based applications that send GPS coordinates, timing and identity code of tourists to the cloud server simultaneously. In this application is also given the facility "panic" is a facility that can be used by member group tourist to send a sign of confusion to their tour leader. Tour leader can see all the positions of his group members through the mobile device screen equipped with google map. This application is designed by using UML diagrams and using real-time firebase database. The test results of this application, show tour leader easier to monitor the movement of members of the tour group. Tour group members are also easier to see his own position and see the position of all his group tour.
\end{abstract}

Keywords- group tour monitoring application; real time database firebase application; mobile application;

\section{INTRODUCTION}

Bali Island is one of the main tourist destinations in Indonesia. The island of Bali is very popular among domestic and even international tourists. Bali tourism is very famous for the hospitality of local residents, art, culture and some places famous for the naturalness of tourist attractions. Tourism Bali is still a favorite destination and the largest foreign exchange contributor to Indonesia.

Usually foreign tourists visit Bali in groups and choose tour packages offered by the travel. During a tour at a tourist site, tourists are often too far away from the group and are confused to return to search for their group or tour leader. Similarly the tour leader who lost his tour members will have trouble contacting the missing members. To facilitate monitoring of the movement of tourists we can utilize technology Global Positioning System (GPS). This GPS data which contains the coordinates of the position of an object on earth sent to the server simultaneously every time span. The server will collect data about the object code, the object's position data and the time the object's position is sent to the server.

Mobile applications with android operating system can be used to transmit GPS data from a moving object. The application will activate the GPS device and get the satellite response from the object coordinate position and send it to the server. This android app can be developed by adding alert or "panic" facilities that can be used by travelers to contact the tour leader if they are in a state of confusion. Tour leaders or the travel management who are located at the office can also contact members to provide group or individual warnings. So that coordination in his goup tour can be maintained.

\section{RELATED WORK}

Research from Beeco Hallo \& Brownlee in 2014, suggests that the Global Positioning System (GPS) is one useful tool for planning, managing and monitoring recreational activities in the wild[1][2]. GPS is a relatively inexpensive and highly effective tool for collecting data on the movement of tourists [3]. Data with GPS is more accurate for determining object loop than using passive mobile positioning data, where there is Call Detail Record (CDR) data obtained from smartphone operator [4. Patterns of tourist movement in rural areas such as Lake Konstanz and cities in Germany, also use GPS data [5] to determine the behavior of visitors to tourist sites. Tatjana Thimm's research shows that tourists always visit major cities and major tourist destinations on the Lake. GPS data used in research to determine tourist behavior towards tourist sites that are often visited. In addition, with this GPS tracking, data can be obtained from hours of tourism entry and travel leave hours.[6]. Research conducted by combining GPS technology, Google Cloud Messaging (GCM) and Google Map to create android based applications[7]. Applications made by Prashant Belder can help travelers, especially those who first visit Mumbai India in finding the nearest bus stop, bus number information, bus departure and bus destinations.

GPS technology is very helpful in the development of applications that support tourism [8][9]. Applications with 
GPS combined with Google Map are widely used in mobile travel applications such as navigation applications, location determination, mobile tourist information assistant and decision support system software (DSS) in supporting tourism services.

\section{METODOLOGY}

This tourist group monitoring application, is built with several stages, namely the analysis phase using OOA (Object Oriented Analysis) and the design phase using OOD. Implementation of software using object-oriented programming language. Object Oriented Analysis (OOA) is a procedure for identifying software engineering requirements and developing software specifications in terms of software system object models, in which there are interacting objects. The main difference between object-oriented analysis and other forms of analysis is that in an object-oriented approach, requirements are organized around the object, which combines data and functions. They are modeled after real-world objects that interact with the system. In the traditional methodology of analysis, two aspects - functions and data - are considered separately. In the Object Orented Analysis stage there are several steps to be taken [10].

- Define the object. Determine object objects that will interact in the system.

- Define the Organizing object by creating an object model diagram. Defines the structure and hierarchy of objects that will organize object classes. Organize and simplify objects into object classes through the concept of aggregation and inheritance. Possible structures and hierarchies.

- Define internal objects or object attributes. Identify the attributes and services associated with each of these attributes. Attributes are identified from data elements that can characterize an object in its entirety. Services are identified from specific behaviors that can indicate the roles and responsibilities of an object.

- Define the behavior of the object, that is, the action of the object. Objects are acted upon and they themselves act on other objects. Behavior is how an object acts and reacts, in terms of its status change and message delivery

- Describes how objects interact. An object by standing alone is not attractive. Objects contribute to system behavior by collaborating with each other. As an example of the structure of an aircraft object, where there are several components of the aircraft that support each other so that the aircraft can fly. M There are two types of object relations in object-oriented analysis and design [11], namely: Link and aggregation.

\section{A. Object Oriented Design}

Design oriented objects (OOD) involve the implementation of conceptual models produced during objectoriented analysis. In OOD, the concepts in the analysis model, which are technology-independent, are mapped into class implementation, identified problems and interfaces are designed, generating models for solution domains, ie detailed descriptions of how the system will be built on solid technology. Implementation details generally include:

- Class data restructuring (if necessary),

- Implementation of methods, namely internal data structures and algorithms,

- Implementation of controls, and

- Implementation of associations.

Object-based applications can be designed using UML (Unified Modeling Language). UML consists of several diagrams including use case diagrams, Activity diagrams, Class Diagrams and Sequence Diagrams. Use Case diagram is a logical description of a slice of externally visible functionality by user. Activity diagram Is a graph of nodes and flow of control through the steps of proses or computation. Every step of node proses could be concurrent and sequensial. Class diagrams are static models that describe the structure and description of classes and their relationships between classes. The relationships could be association, generalization and a kind of dependency[12]

\section{B. Realtime Database Firebase}

Firebase Realtime Database is a database stored in cloud and multiplatform support such as Android, iOS and Web [13][14] . The data in the firebase will be stored in the JSON structure (Java Script Object Notation) [15]. The firebase database will automatically sync the client application connected to it. A multiplatform application that uses the Android, iOS and JavaScript SDK will receive the latest data updates automatically when the application connects to the firebase server. Some things to consider in building a firebase database structure:

- Avoid multilevel data

- Leveling the JSON tree data structure

- Build data according to scale.

When a group with a data group when the data has a complex relationship between one group and another, for example there is a relationship of one to many or many to many. In this case required index to facilitate update data in the corresponding data group. Firebase Realtime Database provides a complete set of features for managing application security. This feature makes it easier for programmers to authenticate users, enforce user permissions, and validate input. Firebase supported applications run more client-side code than previous technologies. Therefore, the way firebase addresses security may be slightly different than the usual. The common first step in securing your app is to identify your users. This process is called authentication. You can use Firebase Authentication to get users logged in to your app. Firebase Authentication includes drop-in support for common authentication methods like Google and Facebook, as well as email and password logins, anonymous login, and more. 


\section{RESUlt AND DisCUSSION}

This tourist group monitoring application, built with several stages of analysis phase using OOA (Object Oriented Analysis) and design phase using OOD. In the Oject Orented Analysis stage there are several steps to be taken: Find the objects, Organize the objects, Define the internals of the objects [8] (Tutorial Points I Pvt Ltd, 2014). Find the object: in this application there are some object involved that is member group tour (tourist), tour leader (guide) and message. Organize the object: A group tour is led by a tour leader. A tour leader leads several members of the tour group. Describe how the object interact: Tourist can see the position of longitude and latitude position.

This application uses UML in designing the software. UML diagrams used include use case diagrams, activity diagrams, class diagrams, and sequence diagrams.

\section{A. Use Case Diagram System}

- Use Case Login. This use case allows tourist or guide login into system to acces relevant menu according to the user's role. Tourist can see their position on google map that appear on screen mobile device. Tourist also can push panic button to sent alert to guide if they lost position and chating to guide. Guide can view their own position on map and see all user positin that already login into system.

- Use Case Register User. This use case allows tourist or guide make new user name and password. The same user name and password not allowed in database. If user name and password already exists in database then showed display dialog "username or password already exists. Please type another username and password.

- Use Case View Map. This use case allows tourist or guide show google map. The system display google map on screen mobile. First, the system connected to internet to get map in cloud.

- Use Case Group Chating. This use case allows tourist oand guide do chat message each other. User choose other group member to chat. System connected to cloud database firebase then system read signal "receive" message, and display arrived message in chat room.

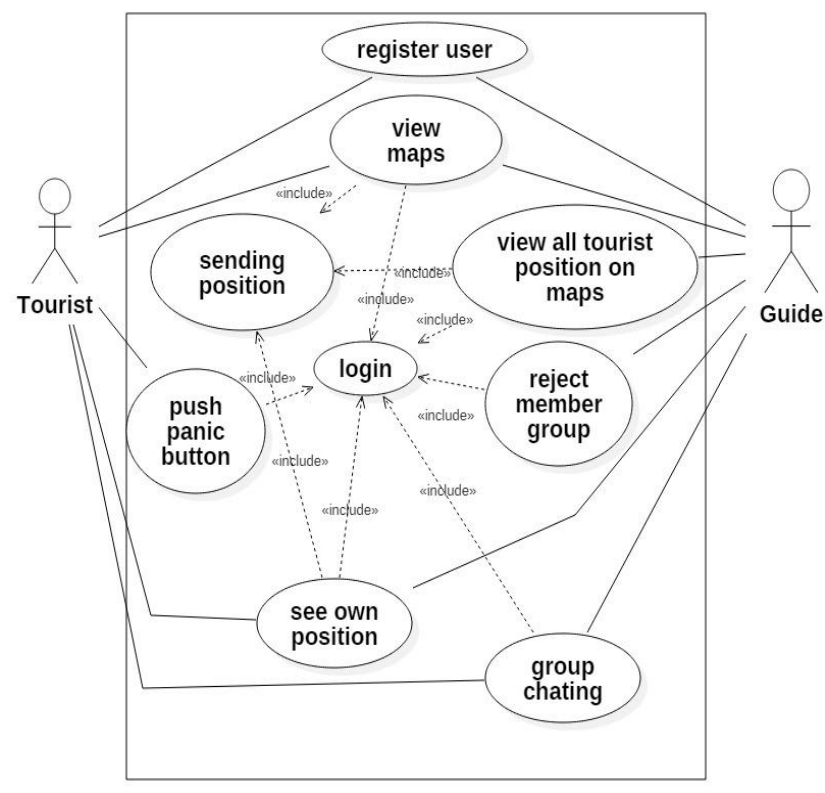

Fig. 1. Use Case Diagram System

- Use Case See own Position. The system display google map and saw tag tourist or guide position on the map. System connect to internet to get map incloud then request coordinate user longitude and latitude GPS position. This coordinate taged on the map.

- Use Case view all tourist position on map. This use case allowed guide to saw all tourist position in one group tour. Tour Group was named by name of guide. The system requested all user coordinate longitude and latitude GPS, their position.

- Use Case Reject Member Group. This use case allowed guide to delete member that invalid enter in tour group. The guide can select invalid tour group members, then delete the member from the tour group list. The system then refreh the list of tour groups.

- Use Case Push Panic Button. This use case allowed tourist for sending panic signal to the guide as tour leader. If tourists feel confused at a tourist spot and need an assistant immediately from the guide, tourists can send panic signals to the guide through the firebase database. The system will display alert signals on the mobile device screen. 
B. Activity Diagram System

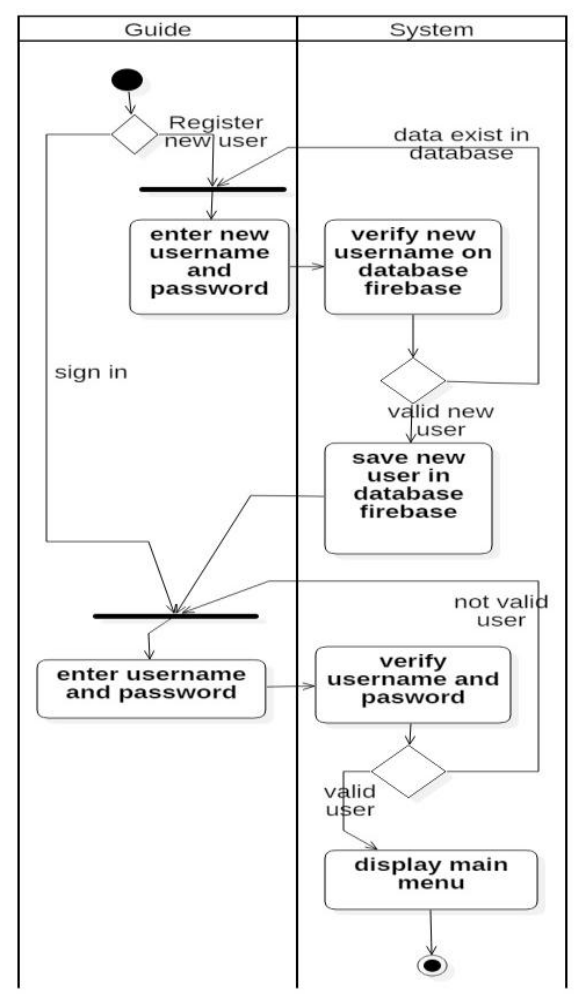

Fig. 2. Activity Diagram Register New User And Sign In

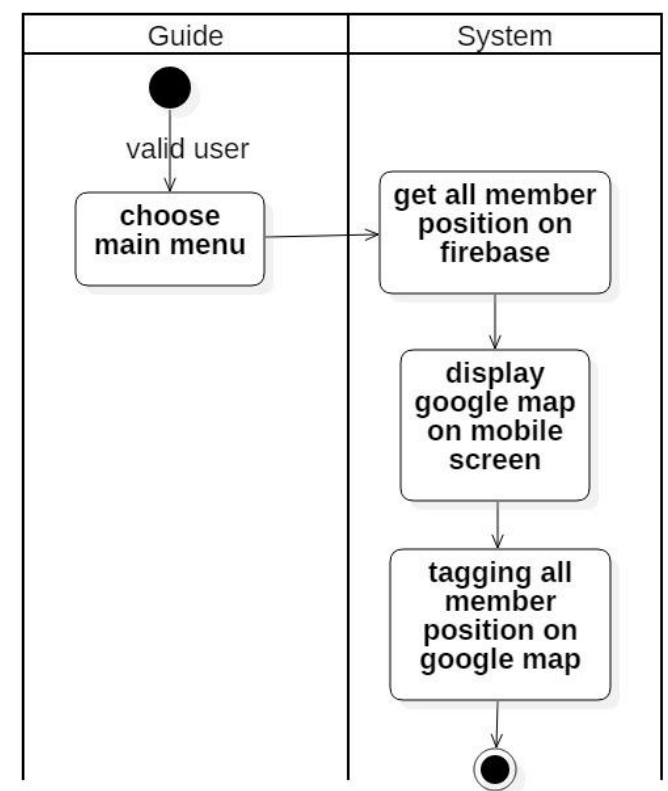

Fig. 3. Activity Diagram display all group tourist position

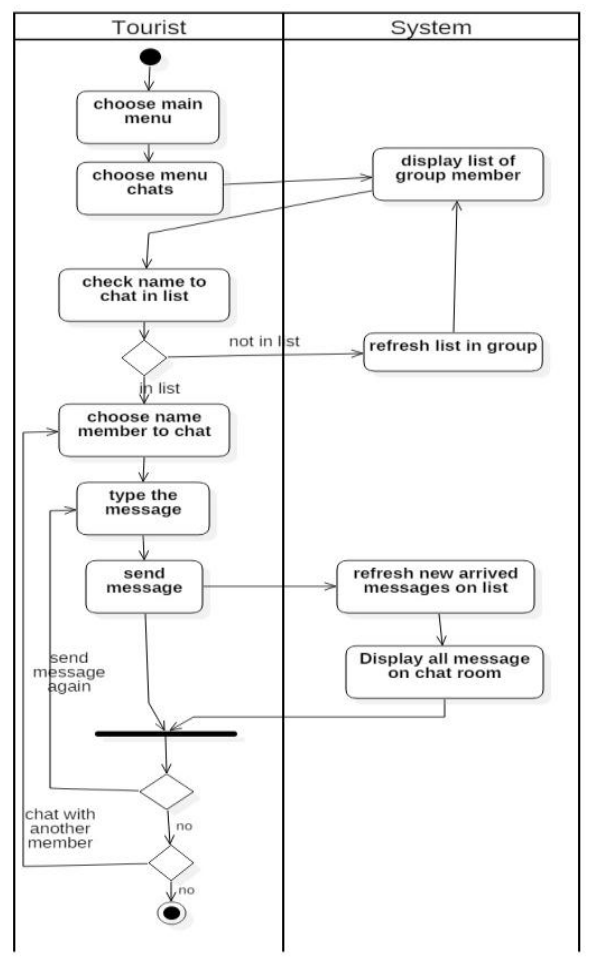

Fig. 4. Activity Diagram Chat Messages

C. Class Diagram System

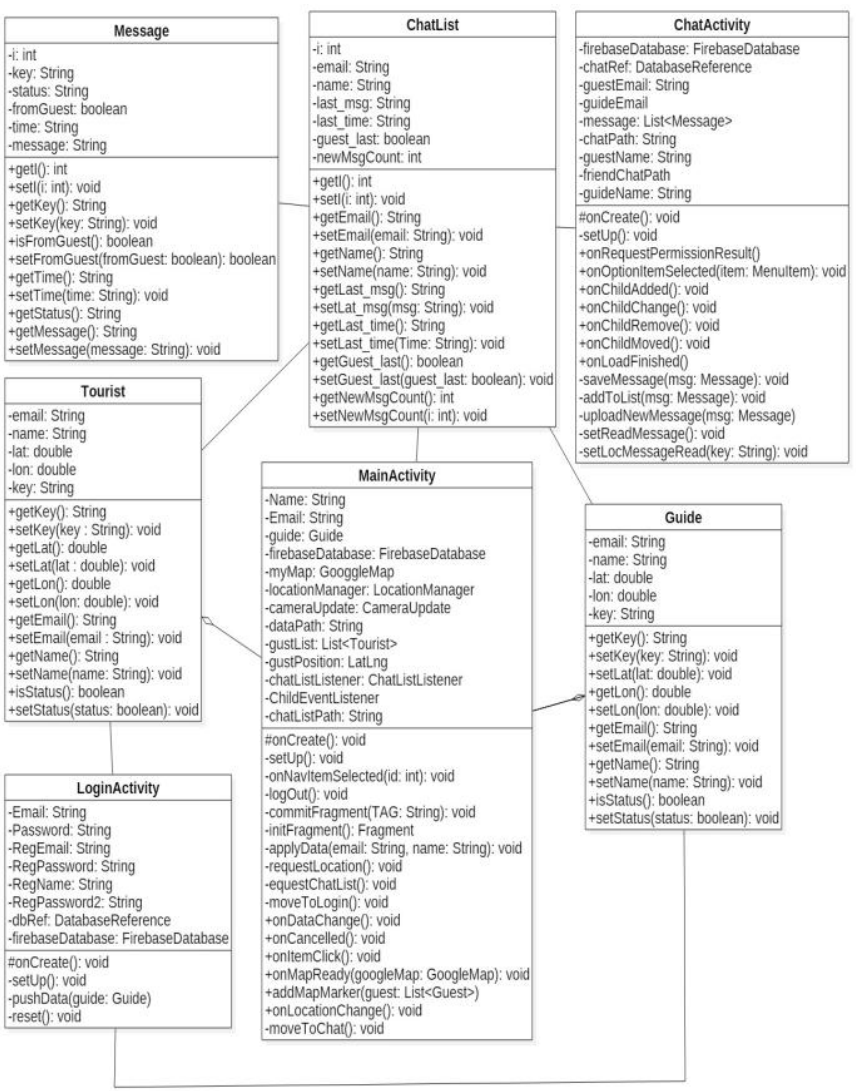

Fig. 5. Class Diagram System 
D. Sequence Diagram System

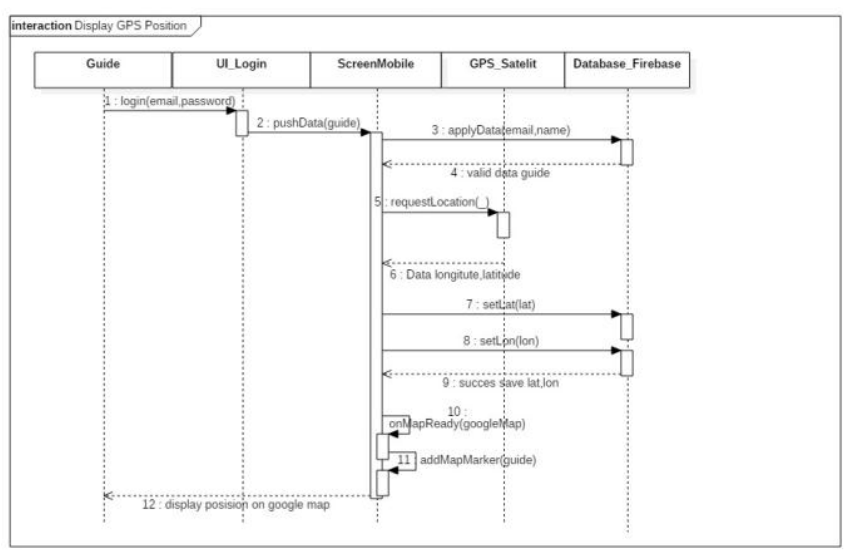

Fig. 6. Class Diagram System

\section{E. Firebase Group Tourist Monitoring Application}

This group tourist monitoring application, saved many data store latitude, longitude coordinates of the guide and tourist position and save a number of messages for chat group activity. The system must update the latitude and longitude data of the guide and tourists every time they move places, so it needs a responsive database and can store large amounts of data. Data updates to all mobile devices must be maintained in real time to maintain application performance.

The realtime firebase database is very suitable for this application. This tourist monitoring application does not require many join queries, so functionally it has similarities from the firebase itself. Firebase is a NoSQL database and data is stored in the JSON (JavaScript Object Notation) tree which is easy to do read and write operations. Firebase has several advantages including: first the database is realtime database where the firebase synchronizes data to all connected devices in milliseconds. Secondly, remain responsive even in offline conditions. The Firebase application remains responsive even though the application is not connected to the claoud network, because the Firebase Realtime SDK saves data to the local disk and automatically updates the data to the server after the network is connected without having to synchronize the client side. Third, it provides many libraries for Android, iOS, JavaScript, and Java.

The developers should be pay attention to the data that will be displayed in the application to be built. This is one of the considerations in creating a firebase database structure. In this group tour monitoring application will display a list of tourists from one tour leader, the tour leader list and a list of chat messages displayed. From the data design that is displayed, we can see that there are two master root data, namely data guide as a tour leader who has several tourists handled and group chat..

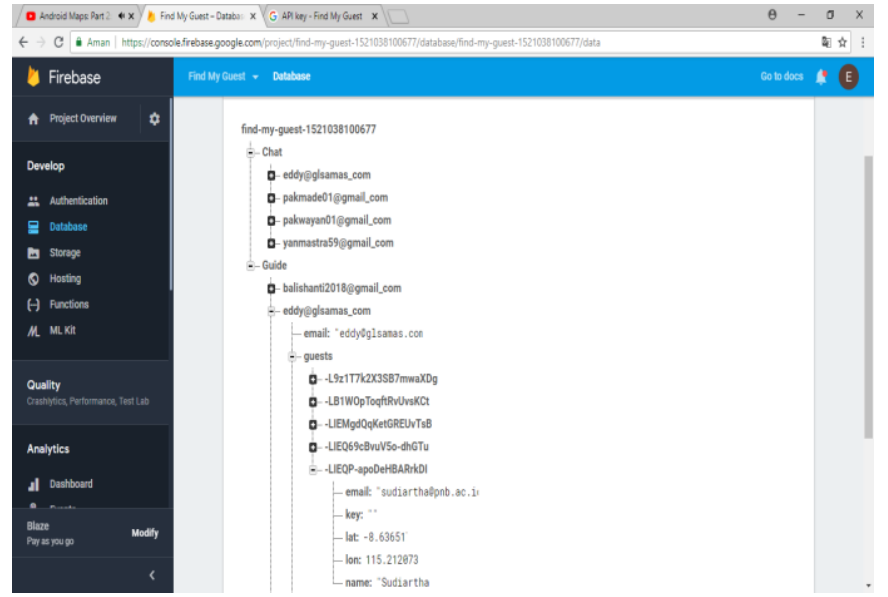

Fig. 7. Firebase Structure System(1)

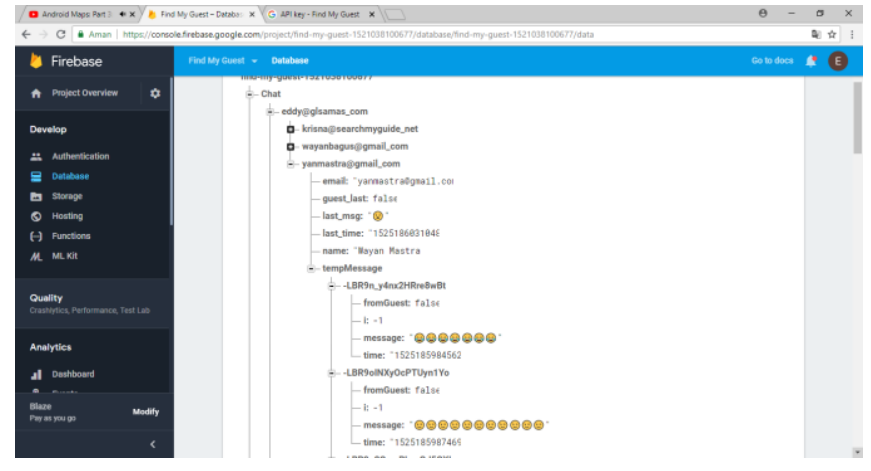

Fig. 8. Firebase Structure System(2)

\section{F. User Interface Implementation}

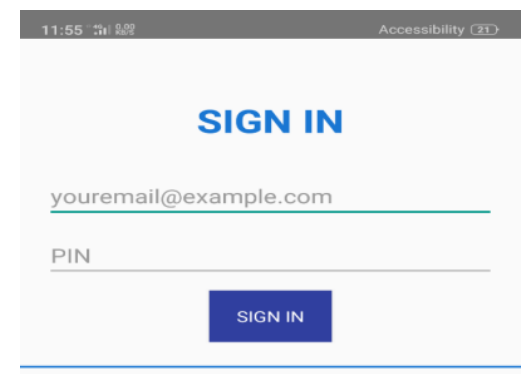

\section{REGISTER}

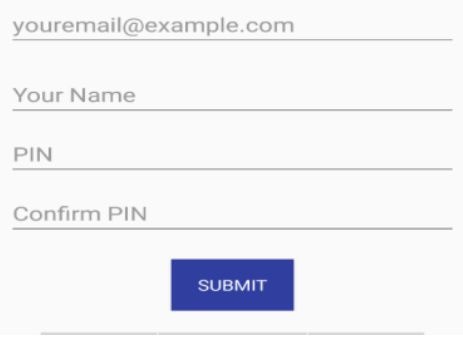

Fig. 9. Form Sign In and Register New User 


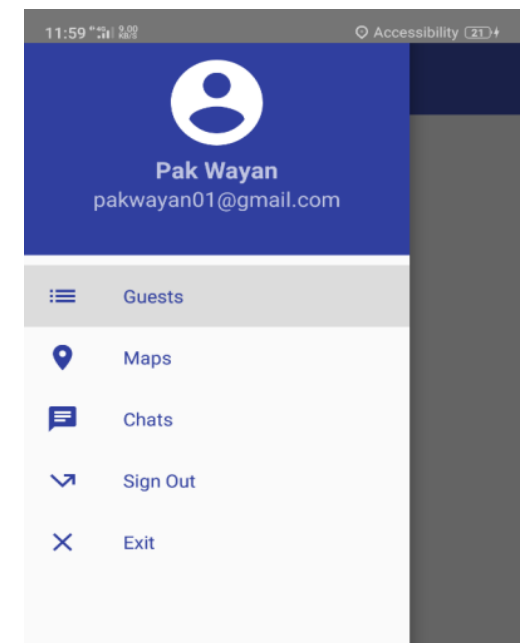

Fig. 10. Main Menu Guide

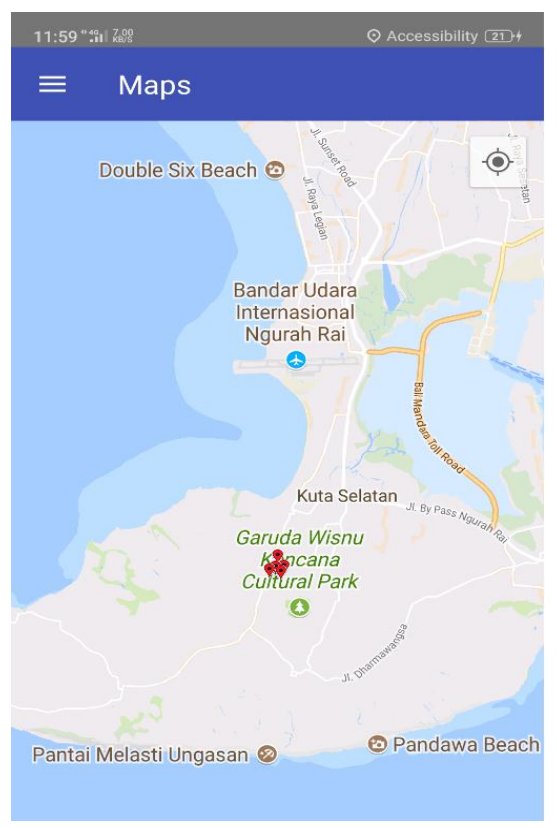

Fig. 11. Display Tourist Location on Map

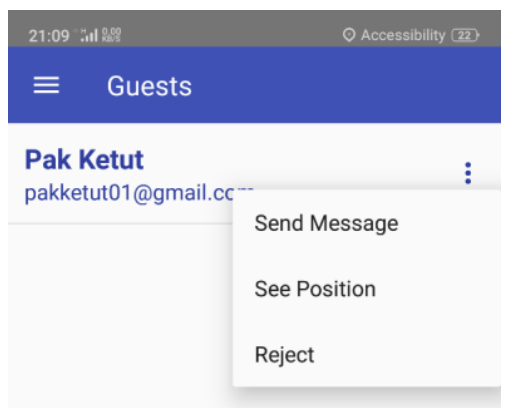

Fig. 12. Display Menu Send Message

\section{CONCLUSION}

Tourist monitoring application requires several main objects, namely member group tour (tourist), tour leader (guide), message and chat list. This tourist monitoring application uses realtime firebase database with its data storage structure in the JSON tree. Adding data to the firebase database will create a node in the JSON structure with an associated key that can be a user id, semantic name or can be created automatically. With the construction of this tourist monitoring group application, communication between member group tours and tour leaders is easier. Tour leaders are easier to monitor the movement and presence of group tour members, so that getting lost in a tourist area can be minimized.

\section{ACKNOWLEDGMENT}

This research was support by the Directorate of Research and Community Service, Director General of Development and Research Enhancement, Ministry of Research, Technology and Higher Education, In accordance with the research contract: Nomor:013/SP2H/LT/DRPM/2018. SP DIPA-042.06.1.40156/ 2018 December 5, 2017.

\section{REFERENCES}

[1] J.A. Beeco, J.C. Hallo, and M.T.J. Brownlee, "GPS visitor tracking and recreation suitability mapping: Tools for understanding and managing visitor use," Landscape and Urban Planning, vol. 127, pp. 136-145, 2014.

[2] N.P. Jagtap, K.A. Patil, S.S. Shakil, and N.S. Ingle, "Mobile activity monitoring system using android spy. international," J. of Adv. Res. in Comp. and Comm. Eng.,Vol. 4, Issue 2, 2015.

[3] S. Karpilo, T. Virtanen, and S. Lehvarvita, "Smartphone GPS trackingInexpensive and efficient data collection on recreational movement," Landscape and Urban Planning, vol. 157, pp. 608-617, 2017.

[4] R. Janika, and A. Rein, "Defining usual environment with mobile tracking data," Proceding on 14th Global Forum on Tourism Statistics, Venice, Italy, pp. 23-25, November 2016.

[5] T. Thimm, and R. Seepold, "Past, present and future of tourist tracking," J. of Tourism Futures, Vol. 2 Issue:1, pp. 43-55, 2016.

[6] H.R. Kristian, H. Henrik, and W. Michael, "The SMS-GPS-Trip method : A new method for collecting trip information in travel behavior research," Telecommunication Policy, vol. 006, May 2014.

[7] B. Prashant, B. Prashant, M. Rajendra, and G. Swapnil, 'Traveler guide using GPS," Intl. J. of Comp. Sci. and Mobile Comp., Vol. 3, Issue. 2, pp. $406-409,2014$.

[8] V. Savchuk, and V. Pasichnyk, "Modern tendention in the use of gps technology in tourism industry," Econtechmod An Intl. Quarterly J., Vol.4, No.3, pg 65-72, 2015.

[9] R. Janika, A. Rein, and T. Margus, "Measuring tourism destinations using mobile tracking data," Tourism Management, vol. 57, pp. 202212, 2016.

[10] Tutorial Point Team, Learn OOAD Object-Oriented Analysis \& Design, Tutirial Point (I) Pvt. Ltd, 2014.

[11] G. Boosch, R. Maksimchuk, M. Engle, B.J. Young, J. Conallen, and K.A. Houston, Object-oriented analysis and design, Addison-Wesley Pearson Education Inc, Boston, USA ISBN 0-201-89551-X, 2007.

[12] J. Rumbaugh, I. Jacobson, G. Booch, The Unified Modelling Language Reference Manual Second Edition, Addison-Wesley Pearson Education Inc, Boston, USA ISBN 0-321-24562-8, 2005.

[13] S. Khedkar, and S. Thube, "Realtime Databases for Applications," Int Intl. J. of Innov. Re. in Sci. Eng. and Tech., Vol. 4(6), 2007.

[14] K. Haena, "NoSQL: A database for cloud computing," Intl. J. of Comp. Sci, and Network, Vol. 3(6), 2014.

[15] N. Srivastava, U. Shree, N.R. Chauhan, and D.K. Tiwari, "Firebase cloud messaging (Andoid)," Intl. J. of Innov. Re. in Sci. Eng. and Tech., vol. 6, pp. 9, 2017. 